\title{
ECOLOGIA DA ICTIOFAUNA DE UM CÓRREGO DE CABECEIRA DA BACIA DO ALTO RIO PARANÁ, BRASIL ${ }^{1}$
}

\author{
Elis Mara Lemes ${ }^{2,3}$ \\ Valdener Garutti
}

\begin{abstract}
ECOLOGY OF THE ICHTHYOFAUNA OF A HEADWATER STREAM OF THE UPPER PARANÁ RIVER BASIN, BRAZIL. Ecological studies were conducted in the ichthyofauna of Cedro, a small headwater stream located in a degraded area of State of São Paulo, Brazil, situated in the upper Paraná River basin. These are the results of two non-consecutive years observations and collections in two biotopes of that stream: a pool and a rapid. The ecological characteristics studied change in space and time. The present richness of species is high (21 species), nine of which are constant, six accessory and six accidental. The diversity is low (0.69 to 2.38), and the numeric predominance, from one to three species, occurred in both biotopes. The most frequent species are Poecilia reticulata (Peters, 1859) (28.1\%), Corydoras cf. aeneus (Gill, 1858) (20.3\%) and Hypostomus cf. ancistroides (Ihering, 1911) (19.8\%). The density ranges from 0.7 to $19.8 \mathrm{specimens} / \mathrm{m}^{3}$. The similarity index indicates high similarity between the ichthyofauna $(45.0 \%$ to $95.0 \%)$ inside the same or contiguous biotopes. The evenness (0.46 to 1.0$)$ is comparable to those found in similar studies carried out in other streams.
\end{abstract}

KEYWORDS. Ichthyofauna, upper Paraná River, biotopes, ecological index.

\section{INTRODUÇÃO}

A fauna de peixes de água doce da América do Sul é diversificada e complexa, com numerosas lacunas no seu conhecimento biológico (VARI \& MALABARBA, 1998). Está distribuída por numerosas correntes de água, incluindo pequenos afluentes de cabeceira e rios caudalosos. Em relação à fauna ictiológica das pequenas correntes de cabeceira, os conhecimentos ecológicos são insatisfatórios. As características da biocenose desses ambientes são praticamente desconhecidas. Correntes de cabeceira normalmente apresentam pequeno volume de água, são rasas e possuem cursos irregulares (WHiTTON, 1975).

Estudaram-se características ecológicas da ictiofauna de uma pequena corrente típica de cabeceira de planalto, situada em área degradada, pertencente à bacia do alto rio Paraná. Trata-se de uma corrente de ordem I na classificação de STRAHLER (1957), com

\footnotetext{
1. Parte integrante da Dissertação de Mestrado da primeira autora.

2. Centro de Aqüicultura da Universidade Estadual Paulista, Via de acesso Prof. Paulo Donato Castellane, Km 5, 14870-000 Jaboticabal, São Paulo, Brasil. (elislemes@ig.com.br)

3. Bolsista do CNPq.
} 
numerosos poções e rápidos alternados, no que se assemelha às demais correntes de cabeceira da região noroeste do Estado de São Paulo (GARUTTI, 1988). Os poções apresentam caracteristicamente substrato friável e maiores largura e volume e menor velocidade das águas. Os rápidos praticamente têm substrato duro, sem deposição de sedimentos. Em algumas épocas do ano, ambos ficam assoreados. $\mathrm{O}$ objetivo foi determinar a riqueza, constância das espécies, freqüências absoluta e relativa, densidade, diversidade, equitabilidade e similaridade das comunidades ictiológicas de dois biótopos dessa corrente, um poção e um rápido.

\section{MATERIAL E MÉTODOS}

Compõe este estudo dois anos não consecutivos de observações e coletas: período I, de julho de 1997 a junho de 1998, e período II, de março de 1999 a fevereiro de 2000. As coletas foram mensais e realizadas durante o dia em dois biótopos seqüentes do córrego do Cedro, um poção e um rápido. $\mathrm{O}$ esforço de coleta em cada biótopo foi de 20 minutos, distribuídos em 15 minutos iniciais de coleta, interrupção de 20 minutos, e mais 5 minutos (tentativas adicionais para capturar exemplares eventualmente remanescentes).

Para as amostragens foram utilizadas duas peneiras com diâmetro de $65 \mathrm{~cm}$ e malha de 3 por $3 \mathrm{~mm}$, uma rede de arrasto de $1,70 \mathrm{~m}$ de comprimento, $1,10 \mathrm{~m}$ de largura e malhagem de 3,6 por 2,0 $\mathrm{mm}$ e uma tarrafa de malha fina com $1,5 \mathrm{~m}$ de altura e malha 7 por $7 \mathrm{~mm}$. Os peixes coletados foram fixados e posteriormente conservados da maneira usual. Amostras das espécies estão depositadas na coleção Ictiológica, Departamento de Zoologia e Botânica, Instituto de Biociências, Letras e Ciências Exatas, Universidade Estadual Paulista, Campus de São José do Rio Preto (DZRP).

As comunidades ictiológicas dos períodos I e II e dos biótopos poção e rápido foram comparadas por meio da riqueza de espécies (ODUM, 1988), freqüências absoluta e relativa (DAJOZ, 1973), constância das espécies (DaJoz, 1973), densidade (Odum, 1988), diversidade, por meio do índice de Shannon (Magurran, 1983), equitabilidade (MAGURRAN, 1983) e similaridade, pelo índice de Morisita (modificado por Horn), um método quantitativo (programa Fitopac, SHEPHERD, 1995). O teste $t$ foi aplicado para testar a significância das diferenças entre as diversidades (MAGURRAN, 1983), considerando-se significante quando $\mathrm{p} \leq 0,05$.

O córrego do Cedro situa-se no município de São José do Rio Preto, São Paulo; possui cerca de $4,4 \mathrm{~km}$ de extensão, desnível médio de $18 \mathrm{~m} / \mathrm{km}$ e trajeto principal no sentido E-W, seguindo a latitude aproximada de $20^{\circ} 52^{\prime} \mathrm{S}$. Nasce e deságua em altitudes de aproximadamente $560 \mathrm{~m}$ e $480 \mathrm{~m}$, respectivamente. Sua bacia de drenagem compreende áreas completamente degradadas, inexistindo mata ciliar. A região de São José do Rio Preto, que integra o Planalto Ocidental do Estado de São Paulo (Almeida, 1964), tem clima tropical quente e úmido, tipo Aw na classificação de Köppen, com duas estações bem definidas: uma quente e chuvosa, de outubro a março, e outra mais amena e seca, de abril a setembro (BARCHA \& ARID, 1971).

No trecho estudado desse córrego, apenas árvores ou arbustos isolados de jambolão, Eugenia jambolana Lamarck, 1789 (Myrtaceae), ocorrem nas suas margens, cuja vegetação marginal é escassa na época seca e razoavelmente desenvolvida na chuvosa. Esta vegetação compreende taboa (Typha sp., Typhaceae), presente na parte final do poção e braquiária (Brachiaria sp., Poaceae), que aparece em pequena quantidade às margens do poção e em grande quantidade do rápido. No substrato do primeiro acumulam-se sedimentos finos, especialmente argila, silte e areia fina, e matéria orgânica,

Tabela I. Variação das dimensões largura, profundidade e comprimento e da velocidade superficial da água, no poção e no rápido do córrego do Cedro, São José do Rio Preto, SP, durante os períodos I (julho/ 1997 a junho/1998) e II (março/1999 a fevereiro/2000).

\begin{tabular}{lcccc}
\hline & \multicolumn{2}{c}{ Poção } & \multicolumn{2}{c}{ Rápido } \\
Variáveis & Período I & Período II & Período I & Período II \\
\hline Largura & $3,0-3,8 \mathrm{~m}$ & $1,6-3,0 \mathrm{~m}$ & $1,0-2,5 \mathrm{~m}$ & $0,8-2,0 \mathrm{~m}$ \\
Profundidade & $8-122 \mathrm{~cm}$ & $8-145 \mathrm{~cm}$ & $12-143 \mathrm{~cm}$ & $12-120 \mathrm{~cm}$ \\
Comprimento & $14 \mathrm{~m}$ & $14 \mathrm{~m}$ & $20 \mathrm{~m}$ & $20 \mathrm{~m}$ \\
Velocidade da água & $0,05-0,14 \mathrm{~m} / \mathrm{s}$ & $0,08-0,22 \mathrm{~m} / \mathrm{s}$ & $0,15-0,62 \mathrm{~m} / \mathrm{s}$ & $0,15-0,36 \mathrm{~m} / \mathrm{s}$ \\
\hline
\end{tabular}

Iheringia, Sér. Zool., Porto Alegre, 92 (3):69-78, 30 de setembro 2002 
na forma de galhos, pequenos troncos, folhas e matéria particulada; em algumas épocas do ano, fica assoreado. No rápido praticamente não há acúmulo de sedimentos, mas também em algumas épocas do ano fica assoreado com areia fina. Algumas variáveis morfo-hidrológicas examinadas durante os períodos de estudos dos dois biótopos revelam elevada plasticidade fisiográfica (tab. I).

\section{RESULTADOS E DISCUSSÃO}

A aplicação de índices ecológicos tem sido pouco explorada em pesquisas com a ictiofauna neotropical, mas pode ser uma ferramenta útil no entendimento da dinâmica das populações das diversas espécies. No córrego do Cedro, a atual riqueza de espécies é elevada, embora sua área de drenagem esteja degradada e a corrente de água sofra assoreamentos constantes. São 21 espécies, compreendendo quatro ordens, dez famílias e vinte gêneros (tab. II). Essa riqueza variou de biótopo para biótopo, variação espacial,

Tabela II. Ictiofauna registrada no córrego do Cedro, São José do Rio Preto, SP, bacia do alto rio Paraná, nos períodos I (julho/1997 a junho/1998) e II (março/1999 a fevereiro/2000), com os respectivos nomes populares e número de registro na coleção ictiológica do DZRP.

\begin{tabular}{|c|c|c|}
\hline Ordem, Família, Espécie & Nome Popular & DZRP \\
\hline \multicolumn{3}{|l|}{ Characiformes } \\
\hline \multicolumn{3}{|l|}{ Characidae } \\
\hline Astvanax altiparanae Garutti \& Britski, 2000 & lambari de rabo amarelo & 2941 \\
\hline A. fasciatus (Cuvier, 1819) & lambari de rabo vermelho & 2942 \\
\hline Piabina argentea Reinhardt, 1866 & lambarizinho & 2943 \\
\hline Serrapinus notomelas (Eigenmann, 1915) & lambari & 2944 \\
\hline Oligosarcus pintoi Campos, 1945 & lambari, bocarra & 2945 \\
\hline \multicolumn{3}{|l|}{ Erythrinidae } \\
\hline Hoplias ef. malabaricus (Bloch, 1794) & traíra & 2946 \\
\hline \multicolumn{3}{|l|}{ Curimatidae } \\
\hline Cyphocharax vanderi (Britski, 1980) & sagüiru, papa-terra & 2947 \\
\hline \multicolumn{3}{|l|}{ Siluriformes } \\
\hline \multicolumn{3}{|l|}{ Gymnotidae } \\
\hline Gymnotus cf. carapo Linnaeus, 1758 & espadinha, tuvira & 2948 \\
\hline $\begin{array}{l}\text { Eigenmannia } \text { cf. virescens (Valenciennes, 1847) } \\
\text { Sigrnopyge }\end{array}$ & espada-folha, tuvira & 2949 \\
\hline \multicolumn{3}{|l|}{ Pimelodidae } \\
\hline Imparfinis mirini Haseman, 1911 & bagrinho & 2950 \\
\hline Rhamdia hilarii (Valenciennes, 1840) & bagre, jundiá & 2951 \\
\hline \multicolumn{3}{|l|}{ Callichthyidae } \\
\hline Aspidoras fuscoguttatus Nijssen \& Isbrücker, 1976 & cascudinho, carretel & 2952 \\
\hline Callichthys callichthys (Linnaeus, 1758) & caborja, tamboatá & 4203 \\
\hline Corydoras cf. aeneus (Gill, 1858) & cascudinho, carretel & 2953 \\
\hline \multicolumn{3}{|l|}{ Loricariidae } \\
\hline Hypostomus cf. ancistroides (Ihering, 1911) & cascudo & 2954 \\
\hline Hisonotus francirochai (Ihering, 1928) & cascudinho & 2955 \\
\hline \multicolumn{3}{|l|}{ Cyprinodontiformes } \\
\hline \multicolumn{3}{|l|}{ Poeciliidae } \\
\hline Poecilia reticulata (Peters, 1859) & lebistes, barrigudinho & 2956 \\
\hline \multirow{2}{*}{\multicolumn{3}{|c|}{$\begin{array}{l}\text { Perciformes } \\
\text { Cichlidae }\end{array}$}} \\
\hline & & \\
\hline Cichlasoma paranaense Kullander, 1983 & acará & 2957 \\
\hline Crenicichla britskii Kullander, 1982 & joaninha & 2958 \\
\hline Geophagus brasiliensis (Quoy \& Gaimard, 1824) & acará & 2959 \\
\hline Tilapia sp. & tilápia & 2960 \\
\hline
\end{tabular}


e de ano para ano, variação temporal (tab. III); foi maior no rápido do período I (20 espécies $v s .16$ no poção) e maior no período I (20 espécies vs. 17 no II). Três espécies não ocorreram no poção: Astyanax fasciatus, Callichthys callichthys e Crenicichla britskii, as duas primeiras amostradas com apenas um exemplar e a última com dois. No ribeirão do Tabajara, situado igualmente em área degradada, UiEDA (1984) registrou 18 espécies. Num córrego afluente direto do rio Pardo, situado em área preservada da floresta mesofítica subtropical, CASTRO \& CASATTI (1997) registraram 19 espécies. A elevada riqueza de espécies da ictiofauna de cabeceira de planalto em regiões degradadas, como a do córrego do Cedro, indica que as espécies adaptam-se às constantes mudanças ambientais e exploram os recursos disponíveis de forma que sua manutenção é preservada.

A freqüência de ocorrência é uma característica que se apresenta variável de corrente para corrente (Uieda, 1984; Garutti, 1988; AraúJo,1996; CAStro, 1997; CAStro \& CASATti, 1997; PaVAnelli \& CARAMASChi, 1997; SMith et al.,1997), ao longo da corrente (Garutti, 1988; Sмith et al.,1997) e no tempo (GARUTTI, 1988). No córrego do Cedro, todas essas variações foram constatadas, incluindo também a variação espacial (tab. III). A freqüência de ocorrência das espécies, nesse córrego, parece ainda sofrer influência da preferência das espécies por biótopos, dos estágios ontogenéticos que cada espécie apresenta e da plasticidade sazonal dos biótopos. Poecilia reticulata apresenta preferência pelo poção, não importando a estação do ano ou o período de amostragem. Hisonotus francirochai tem preferência pelo rápido. Quanto aos estágios ontogenéticos registrados para cada espécie, sempre há espécies em reprodução ao longo do ano nesse córrego, o que

Tabela III. Freqüências absoluta e relativa das espécies coletadas nas estações seca e chuvosa, para poção e rápido do córrego do Cedro, São José do Rio Preto, SP, nos períodos I (julho/1997 a junho/1998) e II (março/1999 a fevereiro/2000).

\begin{tabular}{|c|c|c|c|c|c|c|c|c|c|c|c|c|c|c|c|c|}
\hline \multirow[b]{2}{*}{ Espécie } & \multicolumn{4}{|c|}{ Poção I } & \multicolumn{4}{|c|}{ Rápido I } & \multicolumn{4}{|c|}{ Poção II } & \multicolumn{4}{|c|}{ Rápido II } \\
\hline & Seca & $\%$ & Chuva & a $\%$ & Seca & $\%$ & Chuva & $\%$ & $\mathrm{Sec}$ & $\%$ & Chuva & $\%$ & Seca & a $\%$ & Chuva & $\%$ \\
\hline Astyanax altiparanae & 3 & 1,1 & 8 & 2,1 & 2 & 0,5 & 5 & 1,0 & & & & & & & & \\
\hline A. fasciatus & & & & & 1 & 0,2 & & & & & & & & & & \\
\hline Piabina argentea & 30 & 11,5 & 72 & 19,2 & 12 & 2,7 & 18 & 3,8 & 10 & 4,1 & 4 & 1,1 & 4 & 2,4 & 8 & 1,9 \\
\hline Serrapinus notomelas & & & 2 & 0,5 & & & 10 & 2,1 & & & & & & & & \\
\hline Oligosarcus pintoi & 6 & 2,3 & 7 & 1,9 & 24 & 5,5 & 39 & 8,1 & 21 & 8,7 & 11 & 3,2 & 11 & 6,6 & 15 & 3,6 \\
\hline Hoplias cf. malabaricus & & & 4 & 1,1 & 1 & 0,2 & & & & & & & 1 & 0,6 & 1 & 0,2 \\
\hline Cyphocharax vanderi & & & & & 1 & 0,2 & 2 & 0,4 & 1 & 0,4 & & & & & & \\
\hline Gymnotus cf. carapo & 2 & 0,8 & & & 3 & 0,7 & 3 & 0,6 & 2 & 0,8 & & & 3 & 1,8 & 2 & 0,5 \\
\hline Eigenmannia cf. virescens & & & & & 16 & 3,7 & 19 & 4,0 & & & 3 & 0,9 & & & 1 & 0,2 \\
\hline Imparfinis mirini & 2 & 0,8 & & & 16 & 3,7 & 12 & 2,5 & & & 2 & 0,6 & 2 & 1,2 & 4 & 0,9 \\
\hline Rhamdia hilarii & 3 & 1,1 & & & 2 & 0,5 & 6 & 1,3 & 9 & 3,7 & 2 & 0,6 & 2 & 1,2 & 5 & 1,2 \\
\hline Aspidoras fuscoguttatus & 37 & 14,2 & 1 & 0,3 & 47 & 10,8 & 27 & 5,6 & 8 & 3,3 & 19 & 5,5 & 5 & 3,0 & 32 & 7,6 \\
\hline Callichthys callichthys & & & & & & & & & & & & & 1 & 0,6 & & \\
\hline Corydoras cf. aeneus & 67 & 25,7 & 48 & 12,8 & 202 & 46,3 & 96 & 20,0 & 31 & 12,8 & 37 & 10,6 & 34 & 20,5 & 40 & 9,5 \\
\hline Hypostomus cf. ancistroides & 13 & 5,0 & 26 & 6,9 & 42 & 9,6 & 158 & 33,0 & 15 & 6,2 & 75 & 21,5 & 16 & 9,7 & 197 & 46,7 \\
\hline Hisonotus francirochai & 6 & 2,3 & 2 & 0,5 & 21 & 4,8 & 15 & 3,1 & 4 & 1,6 & 1 & 0,3 & 33 & 19,9 & 57 & 13,5 \\
\hline Poecilia reticulata & 80 & 30,6 & 187 & 49,9 & 36 & 8,3 & 51 & 10,7 & 134 & 55,1 & 177 & 50,8 & 49 & 29,5 & 52 & 12,3 \\
\hline Cichlasoma paranaense & & & 2 & 0,5 & & & 7 & 1,5 & 1 & 0,4 & & & & & & \\
\hline Crenicichla britskii & & & & & 2 & 0,5 & & & & & & & & & & \\
\hline Geophagus brasiliensis & 12 & 4,6 & 15 & 4,0 & 8 & 1,8 & 10 & 2,1 & 2 & 0,8 & 16 & 4,6 & 1 & 0,6 & 6 & 1,4 \\
\hline Tilapia sp. & & & 1 & 0,3 & & & 1 & 0,2 & 5 & 2,1 & 1 & 0,3 & 4 & 2,4 & 2 & 0,5 \\
\hline Total & 261 & 100,0 & 375 & 100,0 & 436 & 100,0 & 479 & 100,0 & 243 & 100,0 & 348 & 100,0 & 166 & 100,0 & 422 & 100,0 \\
\hline Número de spp. & 12 & & 13 & & 17 & & 17 & & 13 & & 12 & & 14 & & 14 & \\
\hline
\end{tabular}


implica no constante recrutamento de jovens pelas populações. Das 20 espécies registradas no período I, no mínimo oito por mês estavam em reprodução. Das 17 do período II, no mínimo sete por mês estavam em reprodução.

A plasticidade fisiográfica do poção e do rápido altera a disponibilidade dos recursos ambientais e a ocupação e permanência das espécies nesses biótopos certamente dependem da habilidade e da exigência biológica de cada uma. A espécie mais freqüente no córrego do Cedro, considerando os períodos I e II, foi P. reticulata, cuja freqüência absoluta variou de nove exemplares em fev/1998 a $81 \mathrm{em} \mathrm{dez/1997.} \mathrm{Hypostomus.} \mathrm{cf.}$ ancistroides, a terceira espécie mais freqüente, variou de três exemplares em set/1999 a 82 em fev/2000.

Oito espécies foram mais freqüentes, com $5 \%$ ou mais do total de exemplares nos dois biótopos estudados. Essas espécies, segundo estudos de CASTRO \& CASATTI (1997) em riacho da bacia do rio Pardo, são tipicamente comedoras de algas (Aspidoras fuscoguttatus, $H$. cf. ancistroides e $H$. francirochai), de algas e insetos aquáticos (Corydoras cf. aeneus e P. reticulata), de insetos aquáticos e terrestres (Piabina argentea e Oligosarcus pintoi) e uma é onívora (Geophagus brasiliensis). O trecho estudado no córrego do Cedro é aberto, com insolação total, o que favorece o desenvolvimento de algas (LOWE-MCCONNELL, 1999).

No córrego do Cedro, a constância das espécies apresenta variação espacial e temporal, assim como variam as categorias de constância (tab. IV). UIEDA (1984), GARUTTI (1988) e PAVANELLI \& CARAMASCHI (1997) também encontraram variação espacial e temporal em seus estudos. UIEDA (1984) e PAVANELLI \& CARAMASCHI (1997) analisaram a constância

Tabela IV. Constância das espécies coletadas no poção e no rápido do córrego do Cedro, São José do Rio Preto, SP, durante os períodos I (julho/1997 a junho/1998) e II (março/1999 a fevereiro/2000) (Cons., Constância; Cat., Categoria; Con, Constante; Ace, Acessória; Aci, Acidental).

\begin{tabular}{|c|c|c|c|c|c|c|c|c|c|c|}
\hline \multirow[b]{3}{*}{ Espécie } & \multicolumn{4}{|c|}{ Período I } & \multicolumn{4}{|c|}{ Período II } & & \\
\hline & \multicolumn{2}{|c|}{ Poção } & \multicolumn{2}{|c|}{ Rápido } & \multicolumn{2}{|c|}{ Poção } & \multicolumn{2}{|c|}{ Rápido } & \multicolumn{2}{|c|}{ Total } \\
\hline & Cons. & Cat. & Cons. & Cat. & Cons. & Cat. & Cons. & Cat. & Cons. & Cat. \\
\hline Astyanax altiparanae & 33,3 & Ace & 33,0 & Ace & & & & & 25,0 & $\overline{\text { Ace }}$ \\
\hline A. fasciatus & & & 8,3 & Aci & & & & & 4,2 & Aci \\
\hline Piabina argentea & 66,6 & Con & 83,3 & Con & 66,7 & Con & 41,7 & Ace & 79,2 & Con \\
\hline Serrapinus notomelas & 16,6 & Aci & 33,3 & Ace & & & & & 20,8 & Aci \\
\hline Oligosarcus pintoi & 33,3 & Ace & 83,3 & Con & 83,3 & Con & 58,3 & Con & 87,5 & Con \\
\hline Hoplias cf. malabaricus & 25,0 & Ace & 8,3 & Aci & & & 16,7 & Aci & 25,0 & Ace \\
\hline Cyphocharax vanderi & & & 25,0 & Ace & 8,3 & Aci & & & 16,7 & Aci \\
\hline Gymnotus $\mathbf{c f}$ carapo & 16,6 & Aci & 41,6 & Ace & 16,7 & Aci & 33,3 & Ace & 45,8 & Ace \\
\hline Eigenmannia cf. virescens & & & 83,3 & Con & 8,3 & Aci & 8,3 & Aci & 50,0 & Ace \\
\hline Imparfinis mirini & 8,3 & Aci & 58,3 & Con & 16,7 & Aci & 41,7 & Ace & 54,2 & Con \\
\hline Rhamdia hilarii & 8,3 & Aci & 50,0 & Ace & 33,3 & Ace & 25,0 & Ace & 45,8 & Ace \\
\hline Aspidoras fuscoguttatus & 25,0 & Ace & 66,6 & Con & 83,3 & Con & 83,3 & Con & 83,3 & Con \\
\hline Callichthys callichthys & & & & & & & 8,3 & Aci & 4,2 & Aci \\
\hline Corydoras cf. aeneus & 100,0 & Con & 100,0 & Con & 91,7 & Con & 91,7 & Con & 100,0 & Con \\
\hline Hypostomus $\mathbf{c f}$ ancistroides & 83,3 & Con & 91,6 & Con & 91,7 & Con & 100,0 & Con & 100,0 & Con \\
\hline Hisonotus francirochai & 33,3 & Ace & 75,0 & Con & 25,0 & Ace & 100,0 & Con & 95,8 & Con \\
\hline Poecilia reticulata & 100,0 & Con & 91,6 & Con & 100,0 & Con & 100,0 & Con & 100,0 & Con \\
\hline Cichlasoma paranaense & 16,6 & Aci & 16,6 & Aci & 8,3 & Aci & & & 12,5 & Aci \\
\hline Crenicichla britskii & & & 8,3 & Aci & & & & & 4,2 & Aci \\
\hline Geophagus brasiliensis & 75,0 & Con & 58,3 & Con & 50,0 & Ace & 33,3 & Ace & 62,5 & Con \\
\hline Tilapia sp. & 8,3 & Aci & 8,3 & Aci & 33,3 & Ace & 33,3 & Ace & 25,0 & Ace \\
\hline
\end{tabular}


em três correntes de água e GARUTTI (1988) a verificou por estações do ano em três diferentes pontos de uma mesma corrente. Esses trabalhos mostram a constância das espécies ao longo da corrente ou de trechos da corrente, mas nenhum analisou a constância em biótopos seqüentes.

A categoria de constância de uma determinada espécie pode ser muito diferente entre uma corrente e outra. A constância parece refletir a habilidade biológica que a espécie tem, nas diferentes fases ontogenéticas, em explorar os recursos ambientais disponíveis num determinado momento do biótopo. Oligosarcus pintoi, $H$. cf. ancistroides e $G$. brasiliensis são comuns como espécies constantes no córrego do Cedro e no ribeirão Tabajara (UIEDA, 1984), enquanto que Hoplias cf. malabaricus, Gymnotus cf. carapo e Rhamdia hilarii são comuns a ambos na categoria acessória. Piabina argentea, O. pintoi, Eigenmannia cf. virescens, A. fuscoguttatus, $H$. cf. ancistroides e $H$. francirochai são espécies constantes no córrego do Cedro e no curso médio do Barra Funda (GARUTTI, 1988). Astyanax altiparanae é constante no ribeirão Tabajara (UIEDA, 1984), na nascente, no curso médio e na desembocadura do Barra Funda (GARUtTi, 1988), no riacho Caracu e no ribeirão São Pedro (PAVAnelli \& CARAmaschi, 1997), enquanto no córrego do Cedro foi apenas acessória no período I, não sendo amostrada no período II.

No córrego do Cedro, $100 \%$ das espécies constantes, $83 \%$ das acessórias e $50 \%$ das acidentais completam o ciclo de vida nos dois biótopos estudados. Entretanto, as espécies restantes, $R$. hilarii (acessória) e $A$. fasciatus, $C$. callichthys e $C$. bristkii (acidentais), devem reproduzir-se em biótopos próximos àqueles pesquisados, pois em outras correntes de cabeceira da região noroeste do Estado de São Paulo completam o ciclo de vida.

A densidade é influenciada pelo volume e pela freqüência dos exemplares. No córrego do Cedro, volume e densidade aparentemente são inversamente proporcionais, com a densidade variando mensalmente (fig. 1). A maior densidade é constatada em set/ 1997, no rápido $\left(19,8\right.$ exemplares $\left./ \mathrm{m}^{3}\right)$ e a menor em ago/1997, no poção $\left(0,7\right.$ exemplares $\left./ \mathrm{m}^{3}\right)$.

Tabela V. Índices de diversidade de Shannon $\left(\mathrm{H}^{\prime}\right)$ e equitabilidade (E) no poção e no rápido do córrego do Cedro, São José do Rio Preto, SP, durante os períodos I (julho/1997 a junho/1998) e II (março/1999 a fevereiro/2000). Letras iguais indicam ausência de diferenças significantes ao nível de $p \leq 0,05$, dentro do mesmo período.

\begin{tabular}{|c|c|c|c|c|c|c|c|c|c|}
\hline \multirow[b]{2}{*}{ Período I } & \multicolumn{2}{|c|}{ Poção } & \multicolumn{2}{|c|}{ Rápido } & \multirow[b]{2}{*}{ Periodo II } & \multicolumn{2}{|c|}{ Poção } & \multicolumn{2}{|c|}{ Rápido } \\
\hline & $\mathrm{H}^{\prime}$ & E & $\mathrm{H}^{\prime}$ & E & & $\mathrm{H}^{\prime}$ & E & $\mathrm{H}^{\prime}$ & E \\
\hline Jul/1997 & $1,76^{\mathrm{a}}$ & 0,85 & $1,80^{\mathrm{b}}$ & 0,87 & Mar/1999 & $1,37^{\mathrm{f}}$ & 0,76 & $1,45^{\mathrm{f}}$ & 0,66 \\
\hline Ago/1997 & $0,69^{\mathrm{c}}$ & 1,00 & $1,75^{\mathrm{c}}$ & 0,84 & Abr/1999 & $1,37^{\mathrm{f}}$ & 0,66 & $1,37^{\mathrm{f}}$ & 0,76 \\
\hline Set/1997 & $1,04^{\mathrm{c}}$ & 0,75 & $1,29^{\mathrm{d}}$ & 0,56 & Mai/1999 & $1,86^{\mathrm{e}}$ & 0,89 & $1,68^{\mathrm{e}}$ & 0,81 \\
\hline Out/1997 & $1,42^{\mathrm{b}}$ & 0,73 & $1,69^{c}$ & 0,77 & Jun/1999 & $1,08^{\mathrm{f}}$ & 0,52 & $1,98^{\mathrm{e}}$ & 0,86 \\
\hline Nov/1997 & $1,17^{\mathrm{c}}$ & 0,60 & $1,85^{\mathrm{b}}$ & 0,80 & Jul/1999 & $1,05^{\mathrm{f}}$ & 0,54 & $1,34^{\mathrm{f}}$ & 0,75 \\
\hline Dez/1997 & $1,15^{\mathrm{c}}$ & 0,55 & $1,83^{\mathrm{b}}$ & 0,74 & Ago/1999 & $1,36^{\mathrm{f}}$ & 0,70 & $1,15^{\mathrm{f}}$ & 0,71 \\
\hline Jan/1998 & $0,82^{\mathrm{c}}$ & 0,46 & $1,56^{\mathrm{c}}$ & 0,61 & Set/1999 & $1,18^{\mathrm{f}}$ & 0,66 & $1,31^{\mathrm{f}}$ & 0,73 \\
\hline Fev/1998 & $1,68^{\mathrm{a}}$ & 0,81 & $2,05^{\mathrm{b}}$ & 0,85 & Out/1999 & $1,68^{\mathrm{e}}$ & 0,81 & $1,80^{\mathrm{e}}$ & 0,87 \\
\hline Mar/1998 & $1,86^{\mathrm{a}}$ & 0,81 & $2,38^{\mathrm{a}}$ & 0,90 & Nov/1999 & $1,26^{\mathrm{f}}$ & 0,61 & $1,80^{\mathrm{e}}$ & 0,78 \\
\hline Abr/1998 & $1,30^{\mathrm{b}}$ & 0,81 & $1,19^{\mathrm{d}}$ & 0,57 & Dez/1999 & $1,13^{\mathrm{f}}$ & 0,58 & $1,89^{\mathrm{e}}$ & 0,79 \\
\hline Mai/1998 & $1,39^{\mathrm{b}}$ & 0,76 & $1,15^{\mathrm{d}}$ & 0,55 & $\mathrm{Jan} / 2000$ & $1,39^{\mathrm{f}}$ & 0,78 & $1,23^{\mathrm{f}}$ & 0,69 \\
\hline Jun/1998 & $1,49^{\mathrm{b}}$ & 0,77 & $1,65^{\mathrm{c}}$ & 0,66 & $\mathrm{Fev} / 2000$ & $1,58^{\mathrm{e}}$ & 0,81 & $1,30^{\mathrm{f}}$ & 0,62 \\
\hline
\end{tabular}



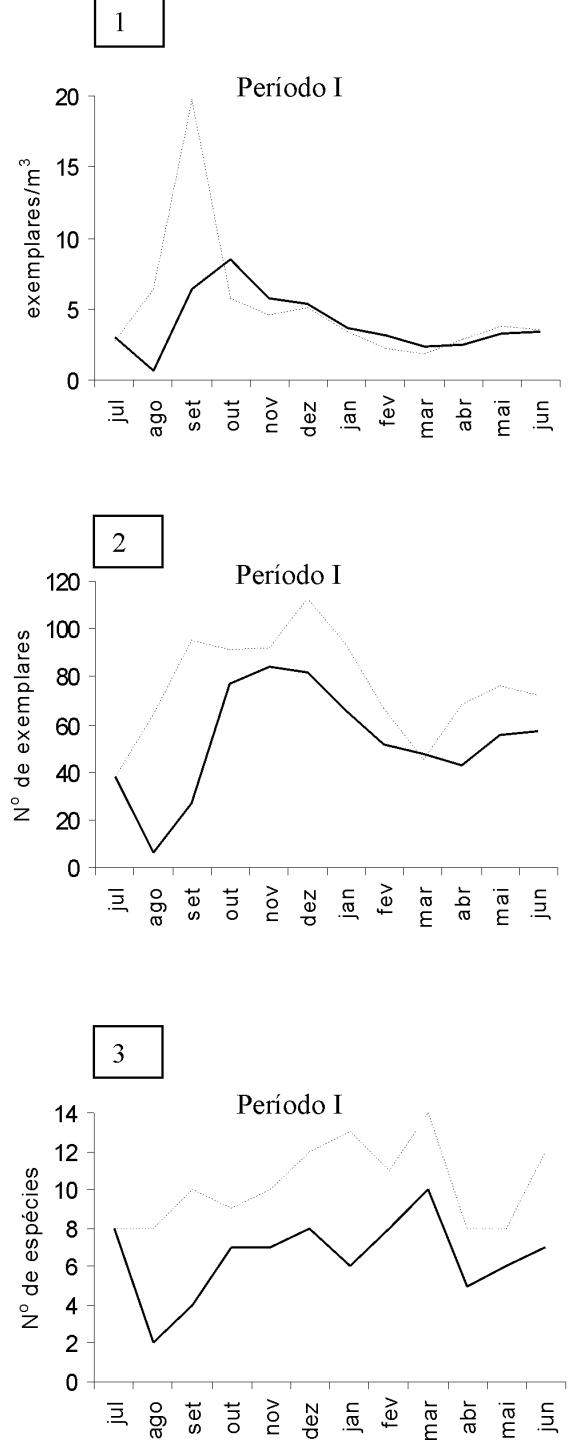
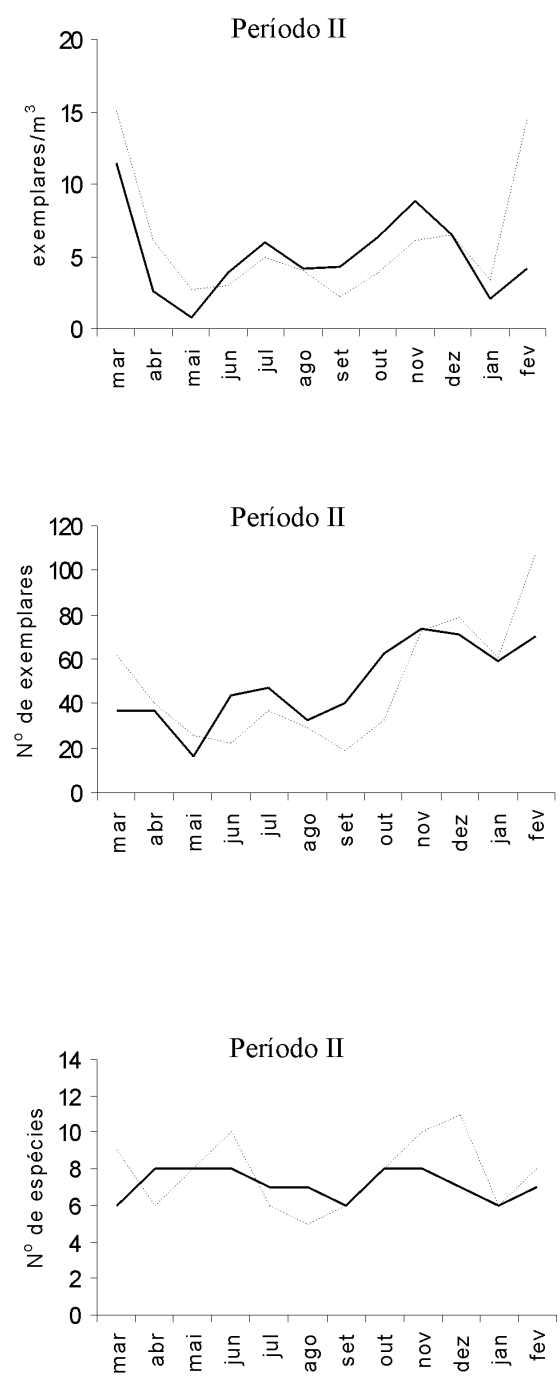

Figs.1-3. Dados mensais da ictiofauna no poção e no rápido do córrego do Cedro, São José do Rio Preto, SP, durante os períodos I (julho/1997 a junho/1998) e II (março/1999 a fevereiro/2000): 1, densidade; 2, número de exemplares; 3 , número de espécies (linha contínua: poção; linha tracejada: rápido). 
Entretanto, em agosto houve um derramamento de óleo queimado (óleo automotivo já utilizado em motores), usado para impermeabilizar uma passarela construída sobre parte do poção. O derramamento, embora pequeno, afetou a ictiofauna do biótopo, sendo registrados apenas seis exemplares pertencentes a duas espécies $(C$. cf. aeneus e $P$. reticulata) (figs. 2, 3). Estes são os menores números obtidos nos dois anos de pesquisa. Em setembro, havia ainda uma película de óleo na superfície da água, mas 27 exemplares de quatro espécies (A. altiparanae, C. cf. aeneus, P. reticulata e G. brasiliensis) foram registrados. Em outubro, não havia mais resquícios aparentes de óleo; oito espécies e 63 exemplares foram capturados.

A diversidade e a equitabilidade das espécies estão relacionadas com a freqüência de ocorrência dos exemplares e com a riqueza de espécies. Quanto menos uniforme é a ocorrência de exemplares, menores são os valores da diversidade e da equitabilidade. No córrego do Cedro, a diversidade e a equitabilidade variaram no tempo (ano para ano, estações do ano e mensal) e no espaço (biótopo para biótopo) (tabs. V, VI). A menor diversidade ocorreu no poção, em agosto/1997, mês em que houve problemas de derramamento de óleo, porém não diferente estatisticamente de setembro, novembro e dezembro/1997 e janeiro/1998. A maior diversidade foi encontrada no rápido, em março/ 1998. O período I apresentou, no geral, diversidade maior que o período II e o rápido, diversidade maior que o poção, com diferenças significantes. Quanto às estações do ano, na seca do período I não há diferença significante entre as diversidades do poção e do rápido; no entanto, a diferença é significante entre ambas na estação chuvosa (tab. VI). Nesse período I, a diversidade do poção é maior na estação seca do que na chuvosa; no rápido, a diversidade é maior na chuvosa do que na seca; nas duas comparações as diferenças são significantes. No período II, a comparação das diversidades do poção e do rápido revela diferença significante nas estações do ano; mas entre as estações em cada biótopo, somente no rápido a diferença é significante. Dos 24 meses em que se calculou a diversidade, em apenas dois o índice de diversidade é superior a 2,0, em 20 meses está entre 1,0 e 2,0 e em dois outros é inferior a 1,0.

A comparação dos índices de diversidade obtidos no córrego do Cedro com os citados na literatura fica prejudicada e limitada, principalmente porque os equipamentos de coleta empregados e o esforço de pesca aplicado não são os mesmos. A eficiência de cada equipamento varia de ambiente para ambiente. Com o mesmo equipamento (peneiras), Pavanelli \& Caramaschi (1997) obtiveram índices de 3,44 para o riacho Caracu e 3,15 para o ribeirão São Pedro; entretanto, essas correntes são afluentes diretos de rio caudaloso. No córrego do Cedro a situação é diferente. A hidrografia regional, na qual está inserido, caracteriza-se pelo aumento gradativo da ordem de corrente, fator importante para considerá-lo como uma corrente típica de cabeceira de planalto.

Os índices de diversidade obtidos para o córrego do Cedro são considerados baixos. Há sempre o predomínio de poucas espécies, geralmente de uma a três. Essa diversidade baixa, embora com riqueza de espécies elevada, pode refletir o grau de degradação ambiental a que está submetida atualmente a sua bacia hidrográfica. Segundo Odum (1988), a diversidade tende a ser reduzida em comunidades que sofrem estresse. Seguem o padrão da diversidade os índices da equitabilidade (tabs. V, VI), que correspondem, no geral, aos valores encontrados por PAVANELLI \& CARAMASCHI (1997) $(0,63$, riacho Caracu; 0,59 , ribeirão São Pedro).

A aplicação de índices de similaridade em biótopos de correntes de cabeceira 
Tabela VI. Valores do índice de diversidade $\left(\mathrm{H}^{\prime}\right)$ e da equitabilidade (E) encontrados para os biótopos e períodos I (julho/1997 a junho/1998) e II (março/1999 a fevereiro/2000) de coletas, por estações do ano e anual, no córrego do Cedro.

\begin{tabular}{|c|c|c|c|c|c|c|c|c|}
\hline \multirow[b]{3}{*}{ Estações/Anual } & \multicolumn{4}{|c|}{ Período I } & \multicolumn{4}{|c|}{ Período II } \\
\hline & \multicolumn{2}{|c|}{ Poção } & \multicolumn{2}{|c|}{ Rápido } & \multicolumn{2}{|c|}{ Poção } & \multicolumn{2}{|c|}{ Rápido } \\
\hline & $\mathrm{H}^{\prime}$ & $\mathrm{E}$ & $\mathrm{H}^{\prime}$ & $\mathrm{E}$ & $\mathrm{H}^{\prime}$ & E & $\mathrm{H}^{\prime}$ & E \\
\hline Seca & 1,88 & 0,76 & 1,87 & 0,66 & 1,61 & 0,63 & 1,97 & 0,74 \\
\hline Chuvosa & 1,56 & 0,61 & 2,16 & 0,76 & 1,51 & 0,61 & 1,72 & 0,67 \\
\hline Anual & 1,78 & 0,64 & 2,11 & 0,70 & 1,61 & 0,60 & 1,89 & 0,70 \\
\hline
\end{tabular}

revela aspectos interessantes do padrão de ocorrência espacial e temporal da ictiofauna. Há épocas em que as ictiofaunas são semelhantes e épocas em que são diferentes, para os mesmos biótopos ou para biótopos contíguos. No córrego do Cedro, as similaridades constatadas entre poção e rápido são: na estação seca, 74\% período I e 79\% no II; na estação chuvosa, $45 \%$ período I e $61 \%$ no II. As similaridades anuais entre ambos são de $59 \%$ no período I e $64 \%$ no II. Na comparação da similaridade em cada biótopo, entre as estações seca e chuvosa no período I, os índices obtidos são de $84 \%$ para o poção e $69 \%$ para o rápido. No período II, a mesma comparação registra similaridades de $95 \%$ para o poção e 59\% para o rápido. PAVANELLI \& CARAMASCHI (1997) encontraram similaridade de $77,0 \%$ entre o riacho Caracu e o ribeirão São Pedro, aplicando o índice de Sorensen.

É importante reiterar que os biótopos estudados no córrego do Cedro, uma corrente típica de cabeceira de planalto, apresentam fisiografia plástica, mudando suas configurações a cada estação do ano, a cada mês ou mesmo a cada chuva. As espécies que compõem as comunidades ícticas desses ambientes devem explorá-los de acordo com suas habilidades e exigências biológicas, de forma que as semelhanças ou diferenças detectadas entre essas comunidades podem refletir a plasticidade abiótica dos dois biótopos.

Agradecimentos. À Denise de Cerqueira Rossa-Feres pelas críticas e sugestões; ao Francisco Langeani Neto pela identificação de parte do material, críticas e sugestões e a Roselene Silva CostaFerreira pela ajuda nos trabalhos de campo (todos do Depto. Zoologia e Botânica, UNESP-SJRPreto). À Gisele Manganelli Fernandes (Depto de Letras, UNESP-SJRPreto), pela correção do abstract. Aos referees anônimos pelas críticas e sugestões. Ao Depto de Zoologia e Botânica, UNESP-SJR Preto, pelo uso dos laboratórios e materiais. Ao CNPq, pela bolsa concedida.

\section{REFERÊNCIAS BIBLIOGRÁFICAS}

Almeida, F. F. M. 1964. Fundamentos geológicos do relevo paulista. Geologia do Estado de São Paulo.

Bolm Inst. Geograf. Geol., São Paulo, 41:167-263.

AraúJo, F. G. 1996. Composição e estrutura da comunidade de peixes do médio e baixo rio Paraíba do Sul, RJ. Revta bras. Biol., Rio de Janeiro, 56(1):111-126.

BARChA, S. F. \& ARID, F. M. 1971. Estudos da evapotranspiração na região norte-ocidental do Estado de São Paulo. Revta Ciên., Votuporanga, 1:99-122.

Castro, A. C. L. 1997. Aspectos ecológicos da comunidade ictiofaunística do reservatório de Barra Bonita, SP. Revta bras. Biol., Rio de Janeiro, 57(4):665-676.

Castro, R. M. C. \& CAsatti, L. 1997. The fish fauna from a small forest stream of the upper Paraná river basin, southeastern Brazil. Ichthyol. Explor. Freshwaters, München, 7(4):337-352.

DAJOZ, R. 1973. Ecologia Geral. São Paulo, Vozes. 472p.

GarutTI, V. 1988. Distribuição longitudinal da ictiofauna em um córrego da região noroeste do Estado de São Paulo, bacia do rio Paraná. Revta bras. Biol., Rio de Janeiro, 48(4):747-759. 
Lowe-McConnell, R. H. 1999. Estudos ecológicos de comunidades de peixes tropicais. São Paulo, Edusp. 535p.

MagurRan, A. E. 1983. Ecological diversity and its measurement. London, Chapman \& Hall. $180 \mathrm{p}$.

Odum, E. P. 1988. Ecologia. Rio de Janeiro, Guanabara. 434p.

Pavanelli, C. S. \& Caramaschi, E. P. 1997. Composition of the ichthyofauna of two small tributaries of the Paraná River, Porto Rico, Paraná State, Brazil. Ichthyol. Explor. Freshwaters, München, 8(1):23-31.

Shepherd, G. J. 1995. Fitopac, versão 2.0, manual do usuário. Campinas, Universidade Estadual de Campinas. 86p.

Smith, W. S.; Barrella, W. \& Cetra, M. 1997. Comunidade de peixes como indicadora de poluição ambiental. Revta bras. Ecologia, Rio Claro, 1:67-71.

Strahler, A. N. 1957. Quantitative analysis of watershed geomorphology. Trans. Am. Geophys. Un., Washington, 38:913-920.

UiedA, V. S. 1984. Ocorrência e distribuição dos peixes em um riacho de água doce. Revta bras. Biol., Rio de Janeiro, 44(2):203-213.

Vari, R. P. \& Malabarba, L. R. 1998. Neotropical Ichthyology: an overview. In: Malabarba, L. R.; Reis, R. P. et al. eds. Phylogeny and classification of neotropical fishes. Porto Alegre, Edipucrs. p. 1-11.

Whitton, B. A. 1975. River ecology. Berkeley, University California. 725 p.

Recebido em 19.06.2001; aceito em 04.07.2002 